\title{
Editorial management of the Journal of Biomolecular NMR
}

\author{
Gerhard Wagner
}

Published online: 23 December 2011

(C) Springer Science+Business Media B.V. 2011

A change at the helm, but staying on course.

In 2011, the Journal of Biomolecular NMR completed its twentieth year of successful publication, during which time the journal has played an important role in advancing the use of NMR in molecular biology. Under the leadership of the founding Editor-in-Chief, Kurt Wüthrich, J. Biomol. NMR has seen good times in the early days as well as hard times when the impact factor dropped due to assessment glitches. Thanks to the efforts of Kurt, the journal has climbed back up the rankings and is now again in very good shape.

I had always personally believed that Kurt Wüthrich would lead the journal forever, and as such, it came as a surprise when I received the message that he had decided to step down at the end of 2011. An even greater surprise was to follow, when the publisher approached me to take over from him; a hard act to follow. After much deliberation, I wholeheartedly agreed to accept the position. I have been Associate Editor for several years now and J. Biomol. NMR plays an important role in the area of science which is very dear to me.

In my new capacity as Editor-in-Chief, I will do my utmost to maintain the high quality standards and together with a great team of Associate Editors, a supportive Editorial Advisory board and all the Journal's contributors and readers, a successful future for the Journal of Biomolecular NMR is ensured.

A change in Editorial structure also represents an opportunity to think about changes that could be made to

\section{G. Wagner $(\bowtie)$}

Department of Biological Chemistry and Molecular

Pharmacology, Harvard Medical School, 240 Longwood,

Avenue, Boston, MA 02115, USA

e-mail: gerhard_wagner@hms.harvard.edu improve the journal further. The first thing that we have decided to change is a switch to an online manuscript submission system. The current submission system has had the advantage of a personal interaction with the Associate Editors of the submitters' choice, compared to the more anonymous submission to an online submission system. However, authors will still be able to direct their papers to their Editor of choice and will be able to track the progress of their papers through the peer-review process.

The format of J. Biomol. NMR will not change and we will continue to publish all manuscripts online and in print. We will of course be keeping an eye on developments in the publishing world and given the increasing migration from print to electronic, we cannot exclude that at some time in the future J. Biomol. NMR will be published exclusively online. J. Biomol. NMR already has the online advantages of being able to publish large datasets and animations which can visualize the time course of coherences in pulse sequences or rotating structures.

Together with the team of Associate Editors, I have also thought about new trends in our field of science and the opportunities that these may hold for the journal. For example, the number of papers on biological applications of solid state NMR has greatly increased in recent years and we will carefully follow this trend and where needed will adapt our scope and direction. J. Biomol. NMR will continue to publish regular papers, communications, structure notes and invited perspectives, and will also continue to produce special issues on a variety of topics. The special issues that have been published over the last few years have proved very popular. We are also thinking about new formats of publication that would make data concerning solution NMR more routinely usable for novices and users with a primary background in biology. 
Through these initiatives we strive to maintain the importance that the correct application of NMR technology has in the biological sciences.

I believe that biological NMR will continue to have a great impact in structural biology and in defining biological mechanisms and I hope that J. Biomol. NMR will continue to feature as a major publishing outlet for the publication of advancements in our science.

Finally, I wish Kurt the very best in his retirement from his Editor-in-Chief responsibilities; we are all hugely indebted to him!

January 2012 